\title{
Bei Dao e a Era Glacial: Tradução e Comentários do poema “A Resposta” (回答)
}

\author{
Antonio José Bezerra de Menezes Jr
}

\begin{abstract}
Para mim o Brasil é o país do amor, do improviso, do jeitinho, onde qualquer um dorme burro e acorda gênio, onde o esquerdista de hoje é o direitista de amanhã, onde o direitista de hoje é o chinês de amanhã.
\end{abstract}

Torquato Neto

Abstract: This paper aims to translate and examine the poem "The Answer" by the poet Bei Dao, one of the leading names in contemporary Chinese poetry, especially the post-Cultural Revolution poetry

Keywords: Bei Dao - Misty Poets (Menglong Shiren) - Chinese Contemporany Poetry Scar literature (Shanghen Wenxue) - Cultural Revolution (China, 1966-1976).

Resumo: $O$ presente trabalho tem por objetivo traduzir e examinar o poema "A Resposta" do poeta Bei Dao, um dos principais nomes da poesia contemporânea chinesa, especialmente da poesia pós Revolução Cultural.

Palavras-chave: Bei Dao - Poetas Nebulosos (Menglong Shiren) - Poesia Contemporânea Chinesa - Literatura da Ferida (Shanghen Wenxue) - Revolução Cultural (China, 1966-1976).

\footnotetext{
"Professor Assistente da Área de Língua e Literatura Chinesa do Departamento de Letras Orientais/FFLCH/USP. Email: antonio.menezes@usp.br.
} 
Menezes Jr, A. - Bei Dao e a Era Glacial: Tradução e Comentários do poema “A Resposta” (回答)

\section{Introdução}

Esta frase de Torquato é bastante significativa da visão que se tinha dos estudantes chineses, na passagem da década de 1960 para 1970, como agentes da mais completa realização do modelo comunista. Esta visão tem sua origem na chamada Revolução Cultural (1966-1976) e na recepção que esta teve na França, influenciando fortemente os movimentos estudantis da época. Richard Wolin no prólogo de seu livro "The Wind from the East", uma referência à asserção de Mao Zedong de que os ventos do oriente sobrepujariam os ventos do ocidente, assim resume esse quadro:

The Wind from the East represents a modest attempt to capture the meaning of the 1960s the infatuation with Cultural Revolutionary China and, more generally, with what came to be known as Mao Tse-tung Thought. The Maoist fascination began as a marginal phenomenon. But soon, and in ways unforeseeable to the actors themselves, it transformed into a general cultural-political intoxication. At a certain point, it seemed that le tout Paris was in the grips of left-wing political vortex. (WoLIN 2010: 6-7).

Um exemplo dessa influência é o filme "La Chinoise" (1967) de JeanLuc Godard que retrata um grupo de estudantes franceses maoístas e sua adesão aos princípios e métodos da Revolução Cultural chinesa.

Contudo, o verdadeiro significado da Revolução Cultural somente começou a ser revelado após a morte de Mao Zedong em 1976 e a consolidação do poder de Deng Xiaoping a partir de 1978. O quadro de violências e arbitrariedades praticadas durante a Revolução Cultural é quase inimaginável. O sinólogo norte-americano J. K. Fairbank sintetiza: 
Menezes Jr, A. - Bei Dao e a Era Glacial: Tradução e Comentários do poema “A Resposta” (回答)

A Revolução Cultural é vista agora não como uma busca de ideais abstratos, mas sim como 'uma onda sem precedentes de perseguições instigadas pelo Estado, guerra de gangues e violência insana'. E no centro de tudo isso estava a suspeita de conspiração - 'inimigos e traidores ocultos' entre os intelectuais e dentro do PCC - um tema 'tomado de empréstimo diretamente' do stalinismo e de julgamentos ostentadores e execuções em massa. (FAIRBANK e GOLDMAN 2007: 369).

Em junho de 1981, durante a VI Plenária do XI Comitê Central, no documento "Resolução sobre certas questões na história do nosso partido desde a fundação da República Popular da China”, o próprio Partido Comunista Chinês classificou a Revolução Cultural como um grande erro:

O camarada Mao Tsé-tung era um grande proletário revolucionário, estrategista e teórico. É verdade que ele cometeu grandes erros durante a Revolução Cultural, mas se nós julgarmos suas atividades como um todo, suas contribuições para a Revolução Chinesa superam em muito os seus erros. Seus méritos estão em primeiro lugar e seus erros são secundários. (TREVISAN 2009: 256)

$\mathrm{Na}$ Literatura, um dos primeiros romances a retratar o período $\mathrm{da}$ Revolução Cultural foi “Cisnes Selvagens" de Jung Chang publicado no ocidente em 1991 e no Brasil em 1994. Esta obra é uma das mais representativas daquilo que passou a ser denominado a "Literatura da Ferida" (伤痕文学 shānghén wénxué). Jung Chang que na juventude pertenceu à guarda vermelha, o movimento estudantil dirigido por Mao e que foi o principal agente da Revolução Cultural, assim recorda as ações desse grupo:

Lin Biao apareceu pela primeira vez em público como adjunto e portavoz de Mao. Fez um discurso convocando os guardas vermelhos a deixar suas escolas e "esmagar as quatro velharias" - definidas como "velhas idéias, velha cultura, velhos costumes e velhos hábitos".

Após esse obscuro apelo, guardas vermelhos em toda a China ganharam as ruas, dando plena vazão a seu vandalismo, ignorância e fanatismo. Invadiam as casas das pessoas, destruíam suas antiguidades, rasgavam pinturas e obras de caligrafia. Acendiam-se fogueiras para queimar 
Menezes Jr, A. - Bei Dao e a Era Glacial: Tradução e Comentários do poema “A Resposta” (回答)

livros. Muito em breve, quase todos os tesouros das coleções particulares foram destruídos. Muitos escritores e artistas se suicidaram depois de terem sido cruelmente espancados e humilhados, e obrigados a ver as suas obras reduzidas a cinzas. Museus foram invadidos. Palácios, templos, túmulos antigos, estátuas, pagodes, muralhas de cidades - tudo o que fosse "velho" era saqueado. As poucas coisas que sobreviveram, como a Cidade Proibida, só o conseguiram porque o premiê Chu En-lai [Zhou Enlai] mandou o exército protegê-las, e emitiu ordens especificas para que fossem guardadas.

Os guardas vermelhos só iam em frente quando estimulados. Mao saudou as ações dos guardas vermelhos com um "Muito bom mesmo!", e ordenou que o país os apoiasse. (CHANG 2007: 357-358).

No Brasil, o choque provocado por essa literatura está relacionado com a desmitificação de toda uma militância estudantil revolucionária, assim como o estereotipo do chinês na citação de Torquato. Na resenha que escreveu para o romance de Jung Chang e publicado na Revista Teoria e Debate (ligada ao Partido dos Trabalhadores) Bernardo Kucinski mostra-se estarrecido:

Todos nós, que amávamos a revolução, temos que ler Cisnes Selvagens, de Jung Chang. (...) Como pudemos nos deixar enganar tanto, e durante tanto tempo? Como podemos admirar tão profundamente a Revolução Cultural chinesa, que humilhava velhos professores de barbas brancas, e levava ao suicídio militantes dedicados do Partido Comunista, que transformava jovens educados em imbecis raivosos e petulantes, que encobria através de uma onda de terror sofisticado, a incompetência e a senilidade de Mao Tsé Tung? (KUCINSKI 2006). 
Menezes Jr, A. - Bei Dao e a Era Glacial: Tradução e Comentários do poema “A Resposta” (回答)

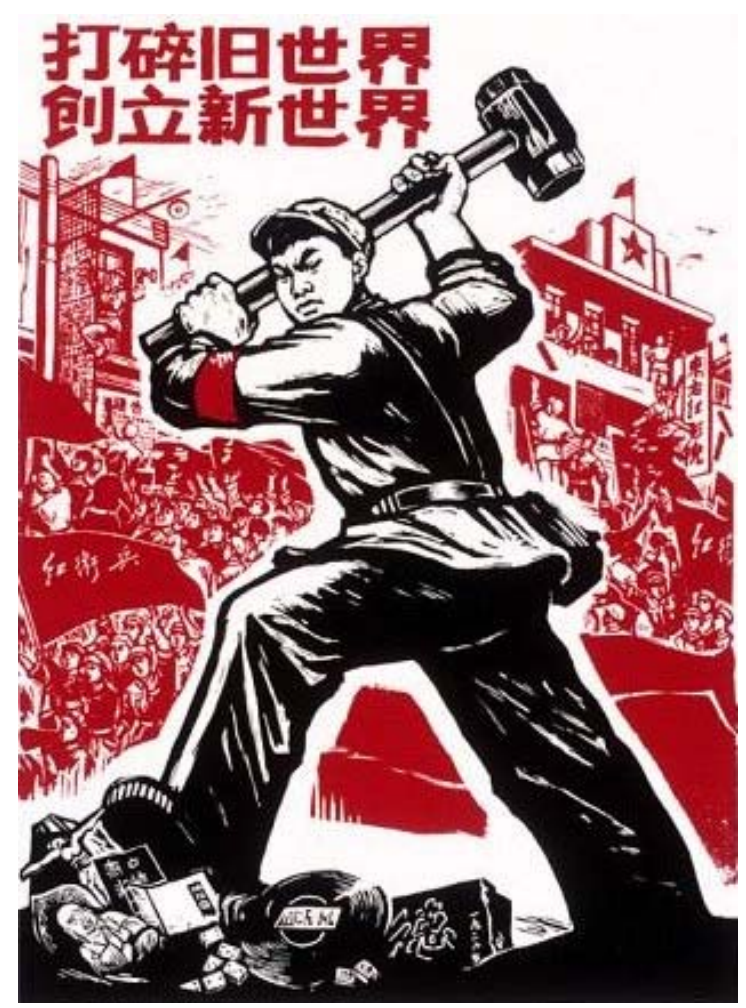

Figura 1: "Destruir o mundo antigo; Forjar o mundo novo" Pôster da Revolução Cultural, 1967

(Fonte:

http://en.wikipedia.org/wiki/File:Destroy_the_old_world_Cultural_Revolution_poster.png Último acesso: 18/10/2011)

No caso da poesia, um dos marcos dessa Literatura pós Revolução Cultural é o poema "A Reposta" de Bei Dao (北岛). Bei Dao é o pseudônimo de Zhao Zhenkai (趙振開) nascido em Beijing em 2/8/1949. Na juventude, participou da Revolução Cultural. Com a desmobilização da Guarda Vermelha em 1969, passou por um processo de "reeducação" trabalhando na construção civil até 1980. Em 1978, juntamente com o poeta Mang Ke, fundou a revista de poesia Jintian (Hoje) que passou a ser o principal veículo de um conjunto de poetas denominados “poetas nebulosos” (朦胧诗人 Ménglóng Shīrén) representando a vanguarda da poesia contemporânea chinesa no período pós Revolução Cultural. Essa denominação foi dada, de modo depreciativo, pela crítica literária da época pois esses jovens poetas não se alinhavam com a estética do realismo socialista e produziam versos cuja interpretação era 
Menezes Jr, A. - Bei Dao e a Era Glacial: Tradução e Comentários do poema “A Resposta” (回答)

considerada vaga e obscura (justamente o significado da palavra 朦胧 ménglóng). Após o massacre de Tiananmen em 1989, Bei Dao permaneceu no exílio até 2006, quando recebeu permissão de retornar para a China. Atualmente é professor de literatura na Universidade de Hong-Kong.

O poema "A Resposta" foi escrito em decorrência do chamado "Incidente de Tiananmen de Cinco de Abril", que mostrou o antagonismo crescente entre o grupo ligado a Zhou Enlai e o grupo ligado a Mao Zedong e a Gangue dos Quatro. Esse incidente é assim descrito pelo sinólogo britânico J. D. Spence:

Em 4 de abril de 1976, véspera do festival anual de Qingming em homenagem aos ancestrais mortos, milhares de pessoas se reuniram em torno do memorial aos mártires da revolução chinesa, que fica sobre um grande frontão triangular, no centro da imensa praça Tiananmen, em frente à Cidade Proibida. Fora nessa praça da Paz Celestial que, em 1966 e 1967, Mao Zedong e Lin Biao tinham saudado o desfile de milhões de guardas vermelhos; agora o povo de Pequim usava a ocasião para prestar homenagem a Zhou Enlai [falecido em 8 de janeiro daquele ano], com coroas, estandartes, poemas, cartazes e flores.

$\mathrm{Na}$ manhã de 5 de abril, uma nova multidão reuniu-se no memorial e descobriu que todos os tributos do dia anterior tinham sido removidos pela polícia. Os protestos acabaram em tumultos e agressões. Incendiaram-se carros de polícia e as mais de 100 mil pessoas forçaram a entrada em vários prédios do governo que cercam a praça. (SPENCE 1996: 605).

No final, centenas de pessoas foram presas e enviadas para acampamentos de "reeducação" e trabalhos forçados e Deng Xiaoping, ligado ao grupo de Zhou Enlai, foi afastado do poder pela segunda vez. 
Menezes Jr, A. - Bei Dao e a Era Glacial: Tradução e Comentários do poema “A Resposta” (回答)

\section{Tradução}

回答

北岛

1 卑鄙是卑鄙者的通行证, 高尚是高尚者的墓志铭, 看吧, 在那镀金的天空中, 飘满了死者弯曲的倒影。

2 冰川纪过去了,

为什么到处都是冰凌?

好望角发现了,

为什么死海里千帆相竞?

3 我来到这个世界上,

只带着纸、绳索和身影,

为了在审判前,

宣读那些被判决的声音。

4 告诉你吧, 世界

我--不--相--信!

纵使你脚下有一千名挑战者, 那就把我算作第一千零一名。

5 我不相信天是蓝的, 我不相信雷的回声, 我不相信梦是假的, 我不相信死无报应。

6 如果海洋注定要决堤, 就让所有的苦水都注入我心中， 如果陆地注定要上升, 就让人类重新选择生存的峰顶。

7 新的转机和闪闪星斗, 正在缀满没有遮拦的天空。 那是五千年的象形文字， 那是未来人们凝视的眼睛。

\section{A Resposta \\ Bei Dao}

Rebaixar é a concessão dos infames, Elevar é o epitáfio dos nobres; Veja como a abóbada dourada Está repleta de sombras deformadas dos mortos.

A Era Glacial já passou, Por que ainda há gelo em toda parte? O Cabo da Boa Esperança já foi descoberto, Por que mil velas contestam o Mar Morto?

Eu cheguei a este mundo Trazendo apenas papel, corda e um contorno, Para trazer diante do tribunal, A voz que já foi julgada:

Deixe-me dizer, Mundo, EU - NÃO - ACREDITO!

Se mil opositores estão esmagados sob seus pés,

Considere-me o número mil e um.

Eu não acredito que o céu seja azul;

Eu não acredito no eco das trovoadas;

Eu não acredito que os sonhos sejam falsos;

Eu não acredito que a morte não seja julgada.

Se o mar está destinado a romper os diques, Que a água salgada inunde meu coração;

Se a terra está destinada a elevar-se, Que a humanidade escolha um novo pico para sua existência.

Uma nova conjuntura favorável e estrelas brilhantes,

Adornam um céu desobstruído;

São os pictogramas de cinco mil anos, São os olhos vigilantes das futuras gerações. 
Menezes Jr, A. - Bei Dao e a Era Glacial: Tradução e Comentários do poema “A Resposta” (回答)

\section{Comentários}

$\mathrm{Na}$ primeira estrofe, logo nos dois primeiros versos, o poeta faz uma referência ao contexto e à motivação do poema: protestar contra os “infames" que desrespeitaram a memória do "nobre" Zhou Enlai no incidente de cinco de abril. Este grande nome da Revolução de 1949 possuía uma aura de nobreza no sentido confuciano do termo, ou seja, não um aristocrata mas um homem de caráter nobre. Durante seu funeral, em 15 de janeiro de 1976, Deng Xiaoping declarou:

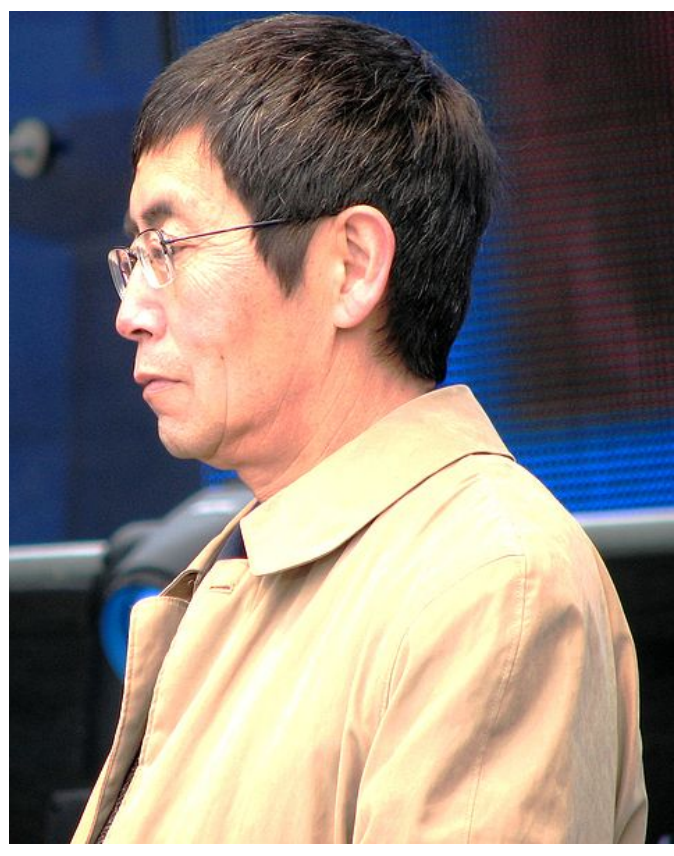

Figura 2: Bei Dao- Foto de 2010.

Fonte:

http://en.wikipedia.org/wiki/File:Bei_Dao.I MG_3385.JPG $(18 / 10 / 2011)$

“Deveríamos aprender com seu estilo fino - ser modesto e prudente, despretensioso e acessível, dando um exemplo com sua conduta e vivendo de maneira simples e trabalhadora" (SPENCE 1996: 604).

Não por acaso, durante a Revolução Cultural, quando a oposição entre Zhou Enlai e Mao Zedong se agravava, este comparou-se a Qin Shi Huang Ti, o primeiro imperador que unificou a China em 221 a.C. (mas ao mesmo tempo um grande tirano), enquanto aquele era depreciativamente apelidado de o Duque de Zhou, um sábio da antiguidade reverenciado por Confúcio. Nos versos seguintes, a "abóbada dourada" é uma alusão à máquina de propaganda do governo e ao próprio governo que, por desrespeitar o culto aos antepassados, aspecto fundamental da religiosidade chinesa, atraia sobre si o infortúnio por descontentar o espírito dos mortos. 
Menezes Jr, A. - Bei Dao e a Era Glacial: Tradução e Comentários do poema “A Resposta” (回答)

Na segunda estrofe, a "Era Glacial" é possivelmente uma referência à Revolução Cultural (1966-1976). Embora se tenha convencionado que ela terminou em 1976, com a morte de Mao Zedong, o período de maior violência terminou em 1969 com a desmobilização da Guarda Vermelha. Os estudantes que a compunham ou foram "reeducados" no campo ou retornaram para as escolas e universidades onde o movimento estudantil foi duramente "enquadrado" pelo exército. Toda a euforia e ardor revolucionário de uma geração foram abruptamente suprimidos, mergulhando toda a sociedade num pesado silêncio e na anulação de toda a individualidade, repetindo o contraponto tenso entre a pretensa pluralidade do "Movimento das Cem Flores" de 1957 e a caça às bruxas da "Campanha Antidireitista" de 1958. Nos versos seguintes, a escolha dos acidentes geográficos sugere o contraste entre uma "esperança" cuja existência é sabida e um "mar morto" em que aparentemente se vive. Essa "esperança" se liga à "nova conjuntura favorável" da última estrofe.

$\mathrm{Na}$ terceira estrofe, encontramos o discurso de modéstia e de autosacrifício preparatório para a estrofe seguinte que é central no poema. Interessante que no segundo verso o poeta diz não possuir sequer um corpo (身) mas apenas a imagem de um corpo (身影), o que a tradutora Bonnie $\mathrm{S}$. McDougall traduziu por "shadow". A questão da imaterialidade desse corpo está relacionado com o problema do esforço de afirmação de uma individualidade num regime coletivizado e adestrado para a constante autocritica: "Devemos confiar nas massas e no Partido. Esses são dois princípios fundamentais. Se duvidarmos deles nada poderemos fazer." (MAO, s/d: 3).

No romance A garota da fábrica de mísseis, no capítulo 18, "Mísseis e poemas nebulosos", Lijia Zhang reproduz o poema "A Resposta" de Bei Dao. ${ }^{2}$ A personagem Pan interpreta que a questão central no poema é o resgate da individualidade:

\footnotetext{
${ }^{2} \mathrm{Na}$ edição brasileira ao menos está faltando a terceira estrofe.
} 
Menezes Jr, A. - Bei Dao e a Era Glacial: Tradução e Comentários do poema “A Resposta” (回答)

\begin{abstract}
"Você não adora o tom desafiador?", perguntou certa vez Pan depois de recitar esse poema de Bei Dao, um importante poeta nebuloso.

Escrito para comemorar o incidente de Tiananmen de 1976, quando centenas de pessoas desobedeceram às autoridades e prantearam publicamente a morte de seu amado primeiro-ministro Zhou Enlai, esse poema era um dos meus favoritos. Eu adorava as imagens novas e pulsantes que transformavam a antiga escrita chinesa na visão futura de seu povo. Pan percebia um significado mais profundo no poema.

"Dá para se ouvir o grito de Bei Dao em favor do individualismo. Este sempre foi o tema da poesia - o que é pessoal, o que é marginal. E não o porta-voz da política." Pela primeira vez, um verdadeiro sentido do eu surgia na poesia chinesa, declarou Pan. Na cultura chinesa, uma pessoa era definida por sua relação com as outras: o confucionismo tradicional enfatizava keji, o autocontrole. A revolução comunista de Mao foi mais longe ainda, tentando destruir o "eu" e a "individualidade". Era-nos exigido pensar como um só, não ser egoísta, como o parafuso perfeito Lei Feng, totalmente dedicado ao Partido. Por entre as linhas enevoadas dos poemas nebulosos, a dignidade do individualismo e da autoexpressão estava sendo claramente restaurada. (ZHANG 2010: 211-212)
\end{abstract}

Ao analisar o poema “Instruções” (海教) de Duo Duo (1951, 多多), outro importante poeta nebuloso contemporâneo de Bei Dao, Yibing Huang também identifica a busca da subjetividade como a principal tarefa dos poetas da geração de Bei Dao, ainda que essa busca esteja condicionada por um discurso histórico em que o processo revolucionário está sempre em jogo:

When the revolution as a political event is over, the utopian drive continues and becomes, perhaps, the most permanent legacy that Duo Duo and his generation have to carry along on the journey of (re)constructing an autonomous subjectivity. This journey, however, is doomed to be endless and hopeless, because, again: "They are men who were born by mistake, who have stopped in a place where life has been misunderstood / What they have experienced-is only the tragedy of birth." They are historically doomed precisely because they are historically conditioned, even if this history itself may have been, from the very beginning, a mistake from their perspective. (HUANG 2007: 36).

$\mathrm{Na}$ viagem que realizou à China em 1974, Roland Barthes também observou que o discurso político chinês da época era "triunfante mas não 
Menezes Jr, A. - Bei Dao e a Era Glacial: Tradução e Comentários do poema “A Resposta” (回答)

triunfalista", tratava-se sempre de "um alerta, um movimento pelo qual se impede continuamente que a revolução se espesse, ingurgite, enrijeça" (BARTHES 2005: 187).

$\mathrm{Na}$ quarta estrofe temos o cerne da "Resposta" e na quinta estrofe os seus desdobramentos. Justamente contrário ao princípio dogmático de confiar no Partido, reproduzido acima e constante no Livro Vermelho, é que o poeta irá dizer com todas as suas forças e com toda a convicção: “eu não acredito”. Essa atitude de descrença irá marcar toda a geração de poetas à qual pertence Bei Dao, como observa Gregory Lee:

En ce qui concerne l'histoire, la trajectoire personnelle de ces jeunes poètes, on peut constater qu'elles se ressemblent, dans la mesure où ils ont été attirés comme des millions d'autres par les idéaux de la révolution culturelle (certains, tels Bei Dao, ont été des gardes rouges actifs), ils ont partagé l'expérience de la campagne profonde où ils ont dû passer jusqu'à 10 ans de leur vie. Ils ont tous vu la réalité socioéconomique de la Chine nouvelle. Ils ont tous été désenchantés par le maoïsme. Ils ont perdu leur foi. Par conséquent, ils sont tous devenus idéologiquement dissidents même sans manifester en activistes comme Wei Jingsheng. Ils partageaient alors une vision des choses, de leur histoire récente, de la réalité chinoise. (LEE 2002: 3).

Contudo é difícil precisar os limites dessa descrença. Nos protestos de Cinco de Abril, observa SPENCE (1996: 605), muitos cartazes pediam a volta ao marxismo-leninismo "genuíno" desvirtuado pela práxis da Revolução Cultural que, através do terror, levou a uma concentração tirânica de poder em Mao e na Gangue dos Quatro. No caso de Bei Dao, nesse momento e nesse poema em particular, é preciso considerar que ele principia o poema procurando desagravar a memória de um grande herói da Revolução de 1949 e termina manifestando uma esperança de mudanças no futuro.

$\mathrm{Na}$ quinta estrofe, o desejo de ruptura da ordem atual, o rompimento dos diques, também é um desejo de abertura do coração e construção de um novo ideal para a humanidade, ou ao menos para o povo chinês, que parece viver demasiado rente à terra, e aparentemente sem esperanças. 
Menezes Jr, A. - Bei Dao e a Era Glacial: Tradução e Comentários do poema “A Resposta” (回答)

O cartunista Henfil, na sua antológica viagem à China "antes da CocaCola", realizada no segundo semestre de 1977, deparou-se com esse quadro de represamento das forças criativas:

Ensinaram os chineses a andar com seus próprios esforços na agricultura, indústria, etc. Mas, devido à propaganda, o chinês só não anda com seus próprios pés na criação intelectual.

Dizem que está mudando, que a distensão começou, que terão mais liberdade. É pagar para ver. Eu já disse que o chinês é polivalente: é soldado-operário-camponês-político. Só não é polivalente completo porque o impedem de ser "criativo". (HENFIL 1986: 223).

Na sexta e última estrofe, o poeta constrói uma imagem de esperança e um desejo de mudança, representado por um céu estrelado, desobstruído, repleto de significados e sinais de vida (as futuras gerações), literalmente oposto à abóbada dourada, opaca e repleta de sinais funestos (sombras fantasmagóricas esvoaçantes) da primeira estrofe. Retomando a distinção entre símbolo e alegoria, segundo Benjamin, podemos dizer que Bei Dao contrapõe ao símbolo decadente da abóbada dourada a alegoria renovada do céu estrelado:

Ao contrário do símbolo, universal concreto que exprime uma visão de totalidade, a alegoria, segundo Benjamin, é representação do outro, de vários outros, mas não do todo. Sua alusividade é pluralista, tende à diversidade. (...) Podemos dizer nesse sentido que o procedimento alegórico é fundamentalmente crítico: não se prestando à construção de naturezas estáticas, ele mostra uma profunda desconfiança da realidade e da linguagem. (HOLLANDA 1980: 59).

Qual é exatamente a esperança que o poeta possui, não está claro. Mas podemos imaginar que aquela voz, mesmo incorpórea, que se levanta na forma de uma poesia, mesmo "nebulosa", de algum modo contribui para degelar o silêncio da Era Glacial. 
Menezes Jr, A. - Bei Dao e a Era Glacial: Tradução e Comentários do poema “A Resposta” (回答)

\section{Referências bibliográficas}

BARThes, R. E Então, China? In: Inéditos v.4 - Política. São Paulo: Martins Fontes, 2005: 182-190.

BEI DAO. Poema “The Answer” (回答) traduzido por Bonnie S. McDougall (extraído do livro The august sleepwalker. New York: New Directions Publishing Co, 1990). Disponível em: <http://www.poetryfoundation.org/archive/print.html?id=180413>. (03/01/2011).
Poema 回答 (texto original em chinês) Disponível em: <http://zhidao.baidu.com/question/15253659>. (03/01/2011).

Chang, J. Cisnes selvagens: três filhas da China. São Paulo: Companhia de Bolso, 2007.

FAIRBANK, J. K.; Goldman, M. China: uma nova história. Porto Alegre: L\&PM, 2007.

HeNfIL. Henfil na China: antes da coca-cola. 17 ed. Rio de Janeiro: Record, 1986.

Hollanda, H. B. de. "O susto tropicalista na virada da década". In: Impressões de Viagem (CPC, vanguarda e desbunde: 1960/70). Rio de Janeiro: Rocco, 1980: 53-87.

HUANG, Y. "Duo Duo: An Impossible Farewell, or, Exile between Revolution and Modernism". In: Contemporary Chinese Literature: From the Cultural Revolution to the Future. New York: Palgrave-MacMillan, 2007: 19-61.

KUCINSKI, B. Resenha do livro Cisnes selvagens, de Jung Chang. Revista Teoria e Debate, Fundação Perseu Abramo, publicado em 22/4/2006. Disponível em: <http://www.fpa.org.br/o-quefazemos/editora/teoria-e-debate/edicoes-anteriores/resenhas-cisnesselvagens-de-jung-chang>.(03/01/2011).

LEE, G. Qu'est-ce que la poésie contemporaine chinoise? ENS-Lettres et Sciences Humaines. Lyon: 24/1/2002. Disponível em: <http://pagesperso-orange.fr/gregorylee/lee_poesie.htm>. (08/07/2010).

MAO T. T. O livro vermelho. São Paulo: Global, s.d.

Saussy, H. Bei Dao and his Audiences. Disponível em: <http://prelectur.stanford.edu/lecturers/dao/daoaudience.html>. (03/01/2011). 
Menezes Jr, A. - Bei Dao e a Era Glacial: Tradução e Comentários do poema “A Resposta” (回答)

SPENCE, J. D. Em busca da China moderna: quatro séculos de história. São Paulo: Companhia das Letras, 1996.

TORquATO N. Tortaquália: obra reunida de Torquato Neto. Organização de Paulo Roberto Pires. Rio de Janeiro: Rocco, 2004: 74.

Trevisan, C. Os chineses. São Paulo: Contexto, 2009.

WoLIN, R. The Wind from the East: French Intellectuals, the Cultural Revolution, and the Legacy of the 1960s. Princeton: Princeton University Press, 2010.

YAO, F.; Bonvicino, R. (orgs.). Um barco remenda o mar: dez poetas chineses contemporâneos. São Paulo: Martins Fontes, 2007.

YeH, M. "Modern Poetry". In: MAIR, Victor H. (ed.). The Columbia History of Chinese Literature. New York: Columbia University Press, 2001: 477489.

ZHANG, L. A garota da fábrica de mísseis: memórias de uma operária da nova China. Rio de Janeiro: Reler, 2010. 